\title{
ADVANCED TECHNOLOGY DEVELOPMENTS IN REMEDIAL STAVE COOLING*
}

\author{
Dustin Vickress ${ }^{1}$ \\ Darryl Metcalfe ${ }^{1}$ \\ David Rudge ${ }^{1}$ \\ Maciej Jastrzebski ${ }^{1}$ \\ Ian Cameron ${ }^{1}$ \\ Barry Hyde ${ }^{1}$ \\ Andrew Shaw ${ }^{1}$ \\ Andriy Ponomar ${ }^{1}$
}

\begin{abstract}
The premature failure of copper staves in the lower stack and bosh is frequently the cause for an interim blast furnace repair at great cost to the blast furnace owner. Protective accretions may form on the stave hot face, but when these accretions are lost the staves can begin to deteriorate both due to abrasive wear from exposure to the descending burden materials and due to thermal cracking from exposure to hightemperature process excursions. These mechanisms can lead to failure of cooling passages, which forces blast furnace operators to shut off these channels, accelerating the rate of copper stave wear. Finger cooler technology was developed to extend blast furnace life by restoring cooling to damaged staves. Evidence for their effectiveness is presented herein in the form of experimental test work and conjugate heat transfer (CHT) analysis carried out using computational fluid dynamics (CFD) simulations. These tests demonstrate that under typical blast furnace excursion conditions, a stave fitted with finger coolers will undergo half the temperature rise of a stave fitted with conventional cigar coolers.
\end{abstract}

Keywords: Copper stave; Stave failure; Campaign life; Blast furnace. 


\section{INTRODUCTION}

Blast furnace operators are presented with the difficult task of maintaining a protective accretion layer on the hot face of the copper stave, which protects the stave against the aggressive conditions of the blast furnace process. If this protective accretion layer is lost, the copper stave is vulnerable to (i) abrasive and erosive wear from direct contact with the burden material; and (ii) thermal cracking on both the stave body and welded steel water pipe connections from exposure to intense heat loads. This damage can lead to water leakages, which must be stopped by turning off affected water channels, reducing the amount of cooling provided to the stave. When cooling is reduced, the rate of damage to the stave accelerates and ultimately leads to expensive blast furnace repairs.

A conventional approach to repairing damaged staves is to install water-cooled cigar or plate coolers, which are inserted through cutouts in the blast furnace wall through the shell and stave, and secured in place using conductive graphitic grout. Hatch has investigated the performance of these coolers and has determined that grouted cigar coolers do not remove a significant amount of heat from the damaged stave due to the thermally insulating effects of the grouting layer. It was observed that the thermal conductivity of the graphitic grout used to establish the thermal connection with the damaged stave is 20 to 100 times less conductive than the highly-conductive stave copper. Additionally, insulating air gaps can form at the grouted connection due expansion separation of the stave body cutout, which further decreases the local conductivity across the gap by an additional 50 to 100 times (i.e. by comparing the ratio of thermal conductivity for $5 \mathrm{~W} / \mathrm{mK}$ graphitic grout vs. air). As a result, these damaged staves remain insufficiently cooled, thus not retaining protective accretions, and continue to wear and be exposed to high heat loads.

Hatch has analyzed the performance benefits of a remedial stave cooler design having a highly-conductive thermal connection instead of grout, in order to restore cooling to damaged staves. This technology has been implemented in the design and construction of novel "finger" coolers, which have direct copper-to-copper contact between the cooler and damaged stave, instead of requiring a grouted connection. The use of direct copper-to-copper contact can dramatically lower stave body temperatures, which means a protective accretion layer is more likely to be retained [1].

This paper presents an analysis by Hatch that compares the performance of finger coolers against conventional cigar coolers through a combination of experimental test work and conjugate heat transfer $(\mathrm{CHT})$ analysis, carried out using computational fluid dynamics (CFD).

\section{ESTABLISHING A HIGHLY-CONDUCTIVE THERMAL CONNECTION}

Finger coolers are inserted through an in situ drilled bore in the damaged stave, similar to the installation of cigar coolers. As an alternative to grouting, finger coolers use an array of spring tensioners, which are tightened in order to radially expand highly-conductive tapered copper wedges inside the bore, thus providing a connection that is both structurally secure and thermally conductive (Figure 1). 


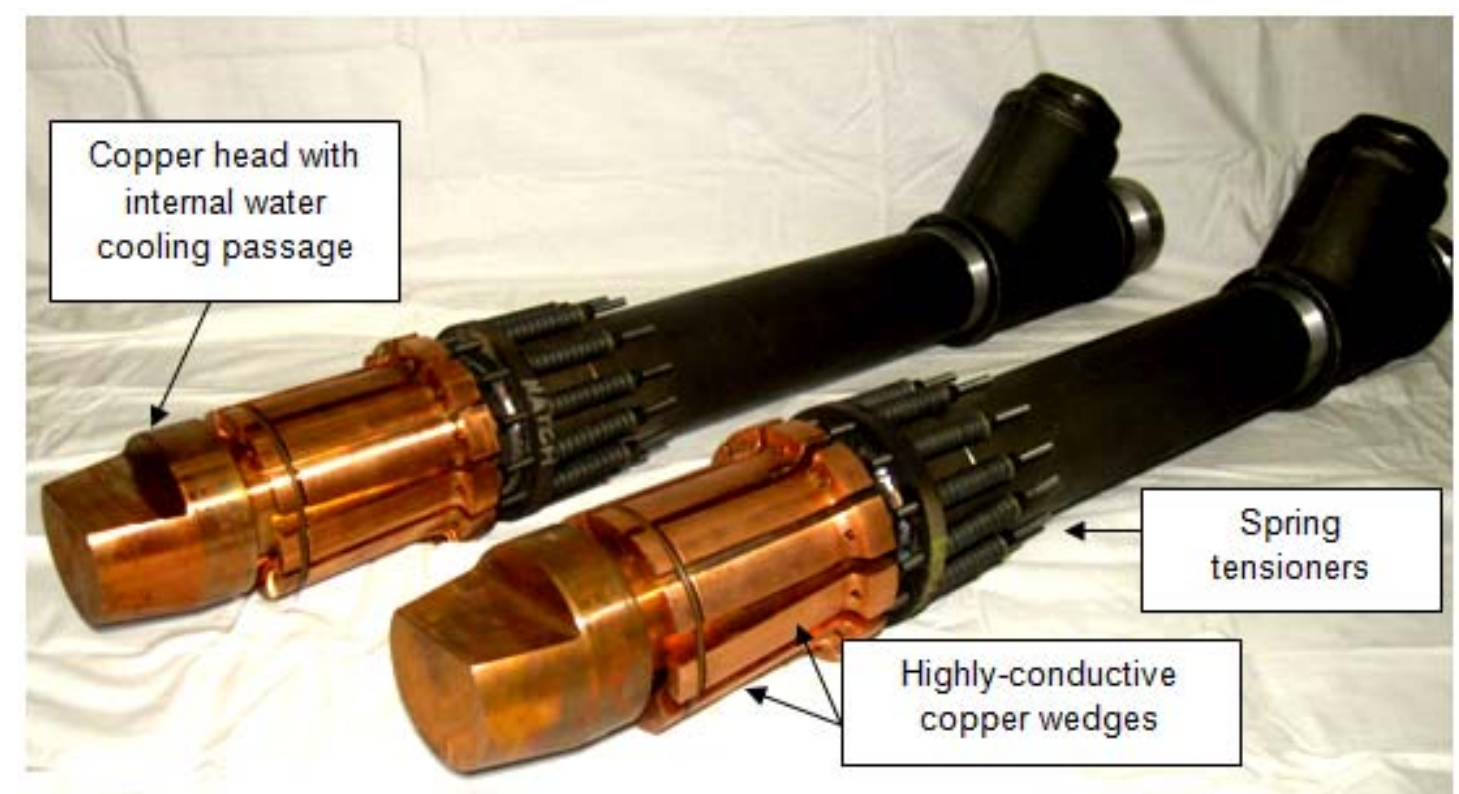

Figure 1. Finger cooler assemblies with highly-conductive copper wedges and compliant spring tensioners

When copper staves expand and contract due to thermal cycling, the highlyconductive thermal connection is maintained by means of the compliant spring tensioners, so the wedges continue to expand when the stave bore cavity grows. In contrast, grouted connections would otherwise break and form insulating air gaps, which further restrict the heat extraction from the damaged stave. As a result, temperatures continue to rise and the thermal cycling continues, thus producing more gaps.

Highly-conductive pressure contacts improve heat extraction from the damaged stave body, leading to lower stave temperatures under all operating conditions, when compared to the use of grouted cigar coolers. Colder staves are known to grow accretions more rapidly and more frequently when compared to higher-temperature staves [1].

\section{EXPERIMENTAL TEST}

Preliminary thermal finite element analysis (FEA) has been previously presented [2]. This work demonstrated the potential for dramatic cooling improvement when direct thermal contact was established via the installation of a finger cooler in a stave. A series of laboratory tests were then completed to compare the thermal performance between highly-conductive copper connections (finger coolers) and grouted connections (cigar coolers). The graphitic grout used in the experiments is considered to have "high-conductivity" (i.e. $5 \mathrm{~W} / \mathrm{mK}$ ), however it is still very insulating when compared to the $\sim 380 \mathrm{~W} / \mathrm{mK}$ conductivity of typical stave copper.

The tests were conducted in a $240 \mathrm{~V} / 6.5 \mathrm{~kW}$ vertically-loaded firebrick-lined electric kiln (Figure 2). The kiln was covered by a $550 \mathrm{~mm}$ diameter by $75 \mathrm{~mm}$ thick copper test block (C11000 ETP 101\% IACS), representing a portion of uncooled stave copper and insulated by Kaowool refractory blanket. The kiln was fitted with thermocouples inserted through vent ports, to monitor refractory wall temperature and internal gas temperature. These temperatures were used to estimate the heat flux applied to the assembly during the tests. 


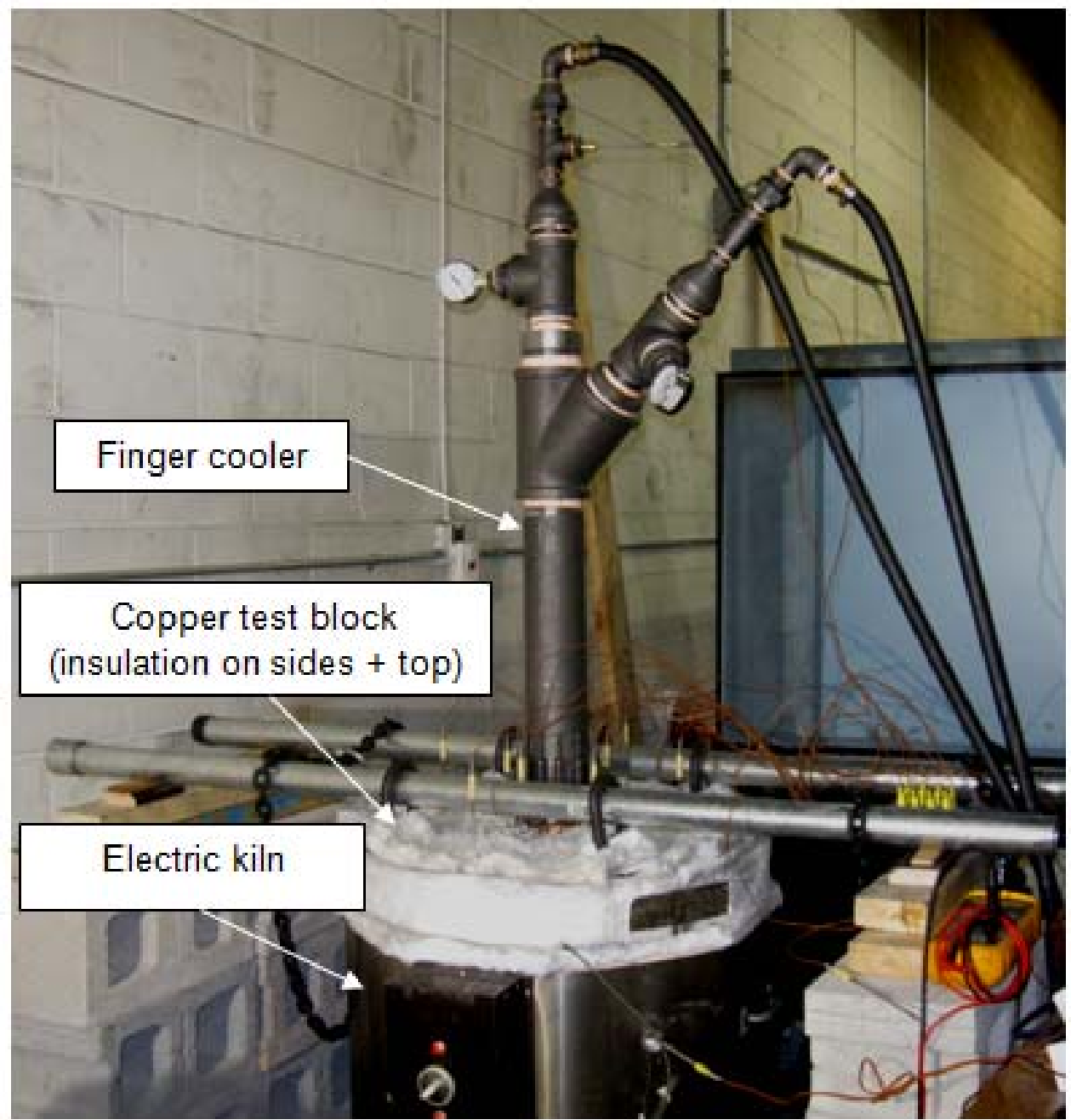

Figure 2. Thermal testing apparatus (finger cooler installation)

For the test, either a single finger cooler or cigar cooler was installed into the copper test block through a $100 \mathrm{~mm}$ diameter bore in the centre (Figure 3 ). The finger cooler spring-loaded tie rods were tightened to apply $5 \mathrm{MPa}$ contact pressure.
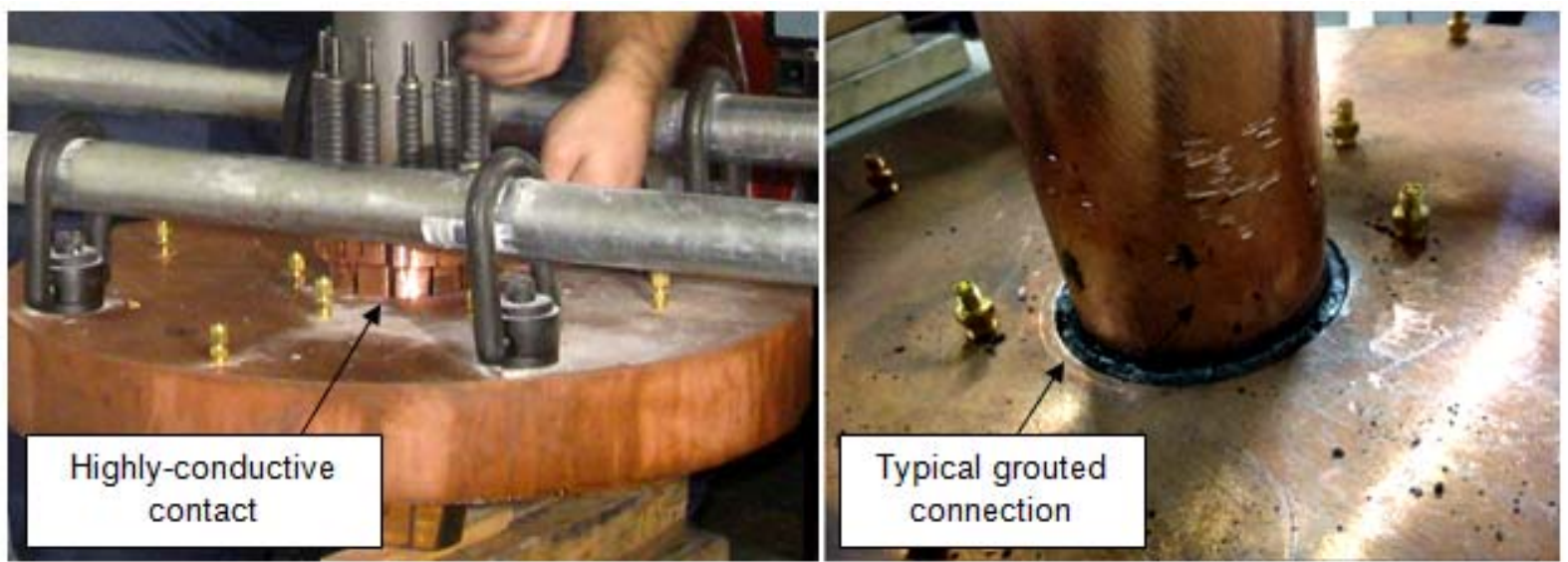

Figure 3. Finger cooler installation (left) and cigar cooler installation (right)

The kiln was operated at full power for both cooler tests, and the results were averaged over a 30-minute hold at steady-state conditions. The temperatures were recorded and are plotted in Figure 4. 


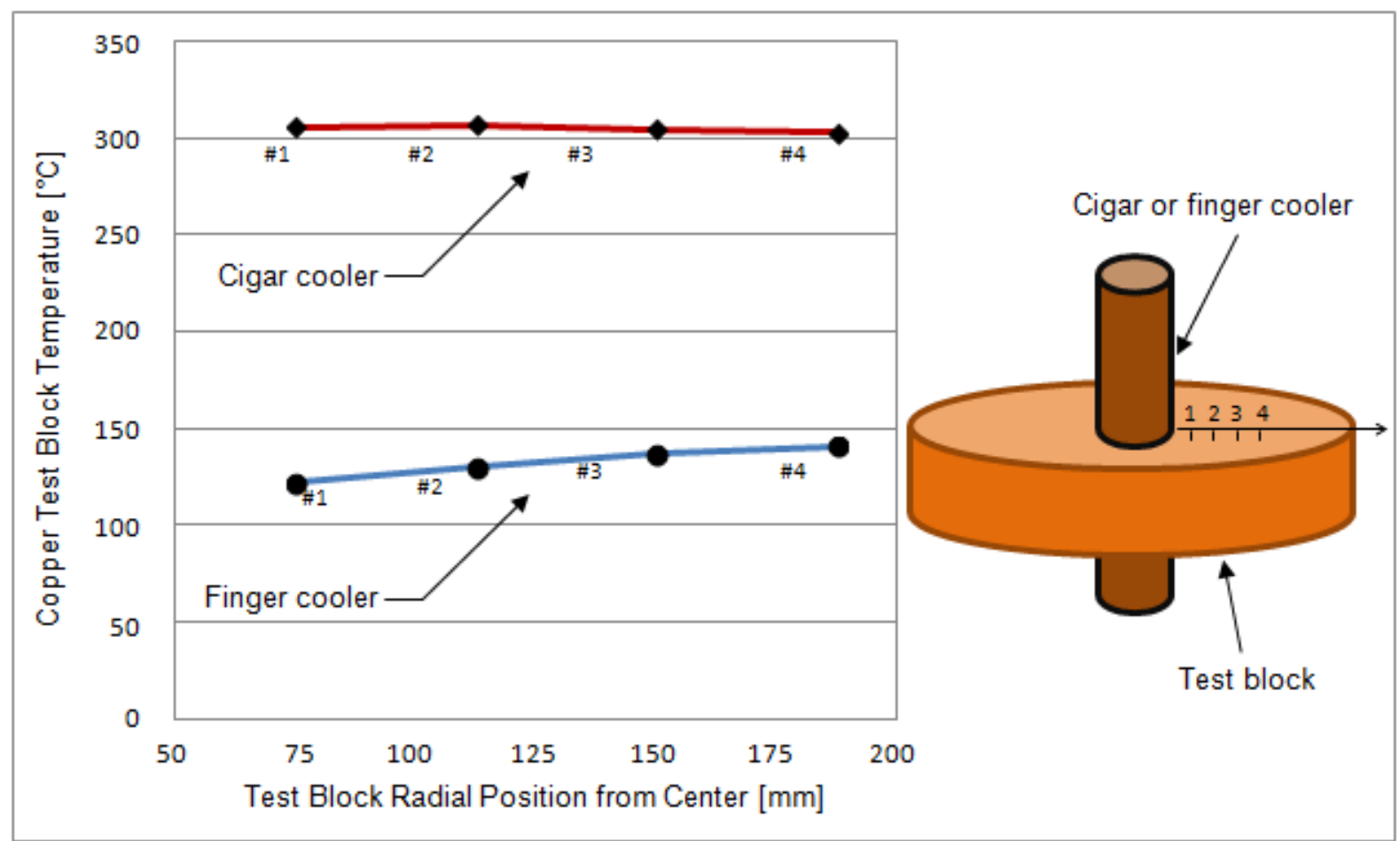

Figure 4. Thermal performance comparison at full kiln power (approximately $20 \mathrm{~kW} / \mathrm{m}^{2}$ heat flux)

According to the results, the highly-conductive wedge connections allow the finger cooler to extract more heat and results in lower copper test block temperatures, which are more beneficial for the formation of protective accretions and blast furnace stave life extension.

The plots show opposite temperature gradients for the two cooler arrangements. The finger cooler demonstrates a reduction in test block temperature towards the bore, which is consistent with the heat flux along the stave body and confirms significant thermal contact is made. In comparison, the cigar cooler case shows a near-constant temperature gradient, with a slight reduction near the test block perimeter insulated by Kaowool. This suggests that the grouted cigar cooler is not providing significant cooling to the test block and heat is preferentially lost through the surrounding Kaowool instead.

\section{HEAT TRANSFER SIMULATIONS}

The lab tests were first performed at a single heat flux condition of approximately 20 $\mathrm{kW} / \mathrm{m}^{2}$, but it is common for copper staves to undergo excursion conditions, exposing them to significantly higher heat fluxes. In order to demonstrate these high-intensity cases, which would require a much greater heat source than a laboratory kiln, a series of 3-D conjugate heat transfer ( $\mathrm{CHT}$ ) simulations were carried out using a commercial computational fluid dynamics (CFD) code [3].

In the simulations, an expanded range of heat fluxes from 10 to $100 \mathrm{~kW} / \mathrm{m}^{2}$ was applied to the test block and test coolers. The significance of including CFD was to capture the variability of heat transfer coefficients at the water-to-copper interface inside of the coolers. The temperature distribution plot for both assemblies for the 35 $\mathrm{kW} / \mathrm{m}^{2}$ case is shown in Figure 5 . In this case, the stave fitted with a finger cooler experienced a maximum body temperature $290^{\circ} \mathrm{C}$ lower than a stave fitted with a grouted cigar cooler. The grouted connection limits the amount of heat extracted by the cigar cooler, whereas the copper wedges of the finger cooler provide a 
preferential path of heat transfer, leading to lower stave body temperatures, which promotes the preservation and regrowth of protective accretion layers.

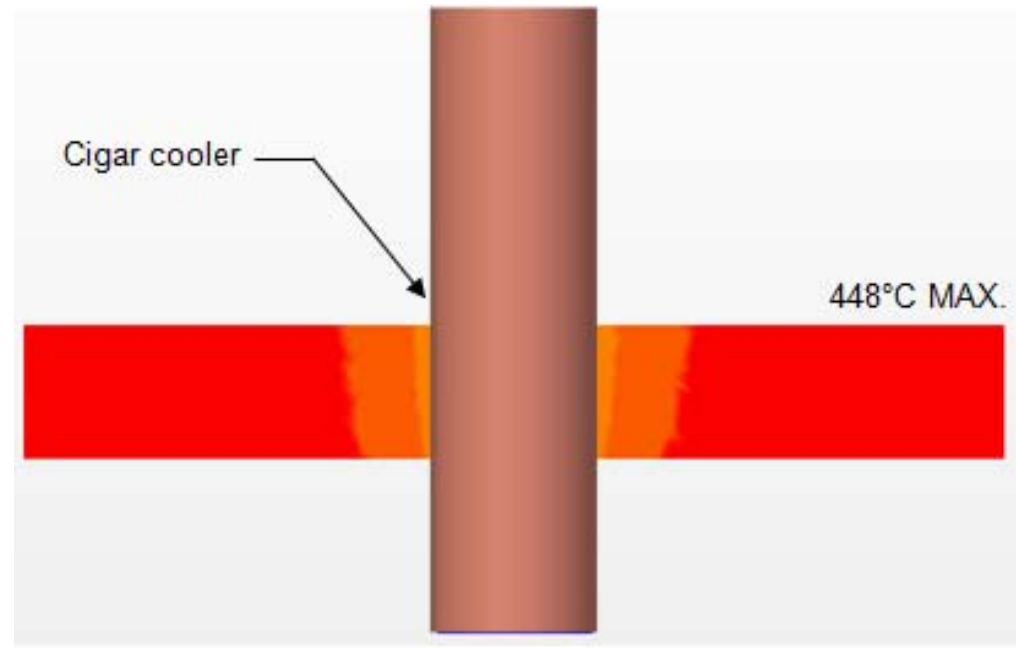

a)

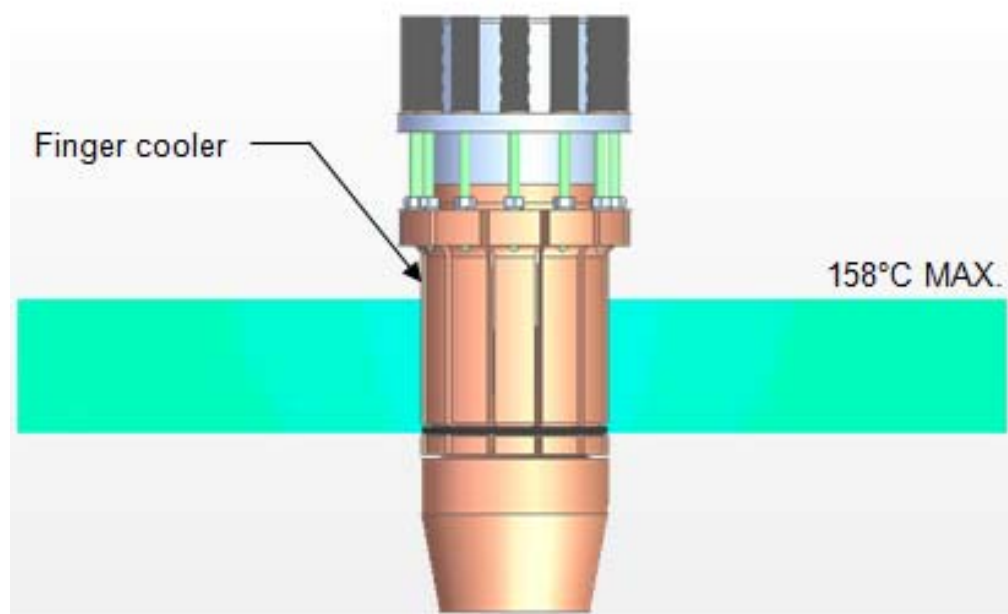

(b)

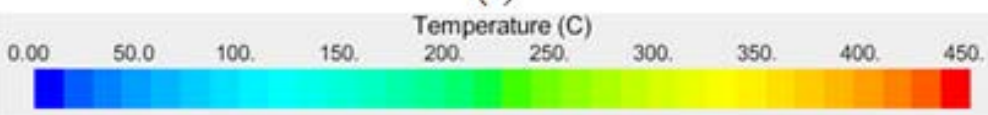

Figure 5. CFD temperature distribution of the copper block/cooler assembly, subjected to a constant heat flux of $35 \mathrm{~kW} / \mathrm{m}^{2}$ from below, using (a) cigar cooler with grout of thermal conductivity $5 \mathrm{~W} / \mathrm{mK}$ and (b) finger cooler

To validate these trials, the lab tests were repeated at $50 \%$ kiln power (i.e. approximately $10 \mathrm{~kW} / \mathrm{m}^{2}$ heat flux), to confirm that the heat transfer simulations correlate with the tested data. The comparison of lab data and simulated data is plotted in Figure 6. 


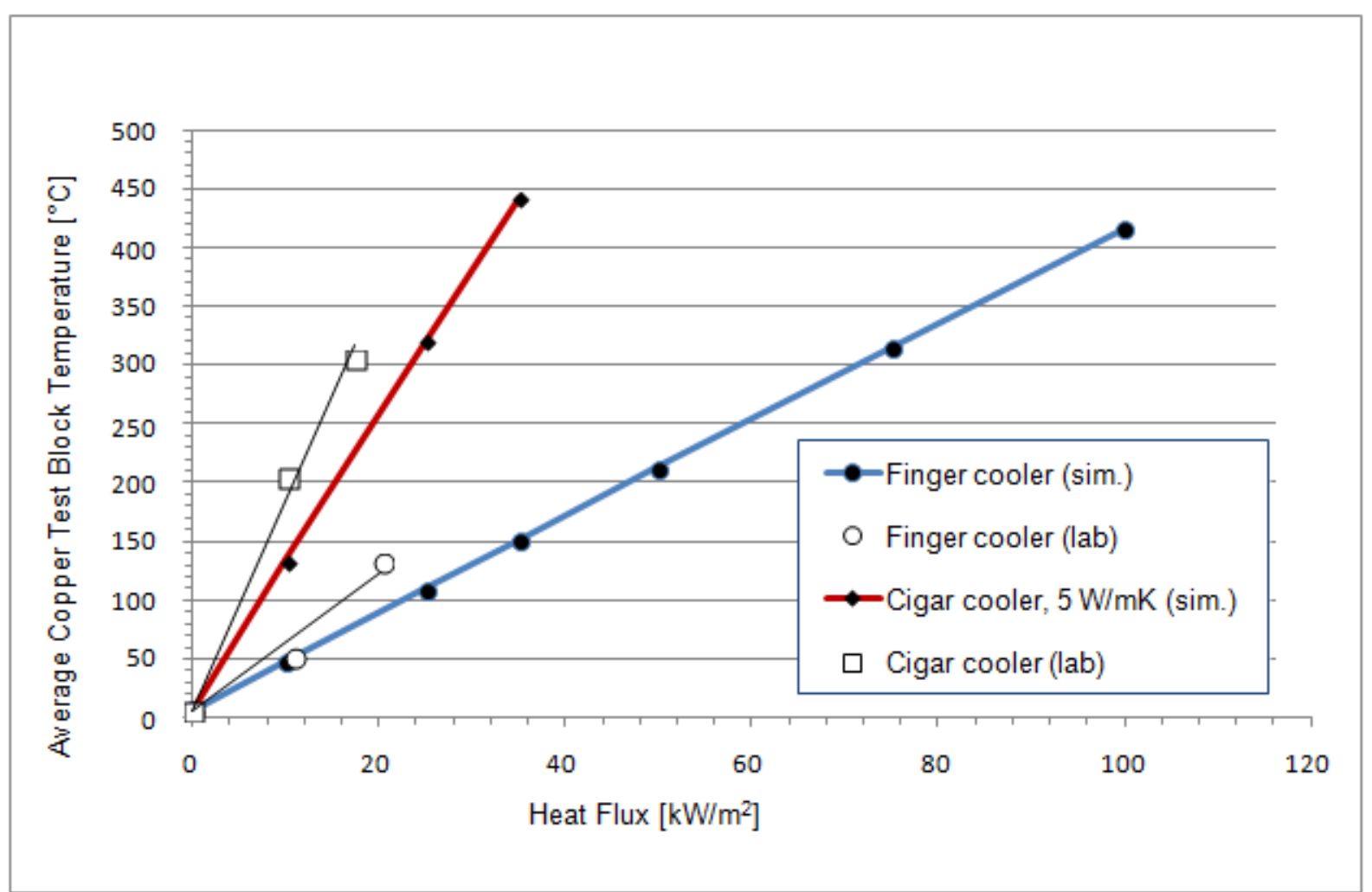

Figure 6. Plotted comparison of simulated thermal performance curves and the laboratory test results for the finger cooler and grouted cigar cooler

The test results for both the finger cooler and cigar cooler indicate less heat was removed than predicted in the simulations, which suggests the actual contact resistance in each assembly was greater than simulated. The simulations assumed the grouted connection was void of gaps, but during industrial practice these gaps are expected to form as a result of thermal cycling and shifting of the stave. However, it is also observed that because the absolute conductivity of the grout is so low compared to the finger cooler copper wedges, it had relatively little impact on reducing stave body temperatures when compared to the highly conductive finger coolers.

The finger cooler simulation also over-estimated the heat removal compared to the tested data, which suggests the contact resistance was somewhat higher than simulated. Further investigation is being completed to quantify the difference between the simulated and actual contact resistances, for use in future conjugate heat transfer models.

By comparing the rate of temperature increase in response to heat flux increase, it was observed that a stave fitted with a grouted cigar cooler will experience a temperature increase rate of 10 to $17^{\circ} \mathrm{C} /\left(\mathrm{kW} / \mathrm{m}^{2}\right)$, whereas a stave fitted with a finger cooler only increases in temperature by 5 to $6{ }^{\circ} \mathrm{C} /\left(\mathrm{kW} / \mathrm{m}^{2}\right)$. According to these results, during a typical heat flux excursion from 20 to $50 \mathrm{~kW} / \mathrm{m}^{2}$, the temperature of the stave fitted with a grouted cigar cooler rises by $400^{\circ} \mathrm{C}$, whereas an identical stave with a finger cooler installed will only rise in temperature by $165^{\circ} \mathrm{C}$.

By providing colder stave body temperatures, high-conductivity finger coolers can lead to the formation of protective accretions that are both more stable and require less time to grow. This represents a significant improvement in the area of stave remediation and is expected to allow operators to extend the life of damaged blast furnace staves. 


\section{CONCLUSION}

Finger coolers with highly-conductive copper contacts provide superior cooling when compared to grouted cigar coolers according to both the lab-scale testing and CFD analysis presented in this paper. This significant improvement in thermal performance is expected to assist operators in maintaining protective accretion layers under a wide range of furnace process conditions.

The results of the experiments and analyses showed that even high-conductivity graphitic grout cannot establish sufficient thermal contact with the damaged stave body to remove a significant amount of heat, when compared to the highlyconductive copper contacts used on finger coolers.

Staves fitted with finger coolers are expected to experience half the temperature rise when exposed to typical excursion conditions compared to a stave fitted with grouted cigar coolers. This improved cooling performance is not expected to degrade over time as a result of stave thermal cycling because the highly-conductive joint is maintained by compliant spring tensioners.

Finger coolers represent an important advancement in the area of blast furnace stave remediation, and are expected to allow operators to significantly extend the life of these staves when they are forced to shut down stave cooling circuits due to (i) abrasive and erosive wear from direct contact with the burden material; and (ii) exposure to intense heat loads that cause thermal cracking to both the stave body and welded steel water pipe connections. Operating with finger coolers can potentially lead to more stable operation when challenged by isolated stave failure.

\section{Acknowledgments}

The authors wish to acknowledge the contribution made by Maher Al-Dojayli and Jennifer Woloshyn who completed the CFD analysis included in this paper.

\section{REFERENCES}

1 Helenbrook, R.; Roy, P.; Hille, H.; 'Correlation of Experimental Data with Analytical Predictions for Blast Furnace Copper Staves', Association of Iron and Steel Engineers, 1998.

2 Shaw, A.; Sadri, A.; Cameron, I; Jastrzebski, M.; Brown, R.; Hyde, B.; 'Preserving Copper Staves and Extending Blast Furnace Campaign Life', Association of Iron and Steel Technology Conference (AISTech 2014) Proceedings, May 5-8, 2014, Indianapolis, USA.

3 CD-adapco STAR-CCM+. http://www.cd-adapco.com/products/star-ccm\%C2\%AE; accessed April $10^{\text {th }}, 2016$. 